for our catalogs? The catalog in its simplest form is an author list of materials. But in order to make the knowledge contained in our books more readily accessible, we in America developed classed and dictionary catalogs. In this way we created bibliographical tools which our patrons are now taking for granted and in all probability will continue to demand. The catalogs in our largest libraries have reached terrifying proportions, so great that some libraries have divided their catalogs in order to break up the huge files. Do we want more added entries and more analytics or would the greater alphabets created by this extension only confound our faculty members and students? Are the details of collation represented in forty-two new rules all essential ones? Are they essential to the great bulk of our collections or can we restrict bibliographical description to our special collections, rare and semirare items? That some libraries are willing to dispense with certain details can be deduced from the fact that 181 college and university libraries are using the $\mathrm{H}$. W. Wilson cards. These cards are exceedingly simple and direct, possibly too simple, but they are restricted to the somewhat popular titles represented in the Standard Catalog.

\section{Several Paths Open}

Several paths are open to the committee sponsoring the new code. My belief is that the first part should be retained with slight modification. Ways and means by which the injunction given in the preface to modify and simplify can be carried out could be indicated by illustration. This might be done either by examples in the text, differentiating them typographically or by issuing a supplementary style manual. In making available to the cataloger the scholarly and detailed fashion by which books may be described, we have at last a comprehensive and effective manual. There are few, if any, rules that will not be used and valued by some library. Let us not pass over them hastily or in the interests of what may now seem to be economy. If we simplify too much, the pendulum will surely swing in the other direction later, and the costs which we should be shouldering now will be passed on to those who will follow us.

By MARGARE'T I. SMITH

\title{
The Code and the University Reference Librarian
}

Miss Smith is superintendent of the reading room, General Library, University of Michigan, Ann Arbor.

I might confess at the beginning that this is the first cataloging code that I have ever read straight through. I found it more interesting than I anticipated and I was so impressed with the wealth of reference material it contains that I am going to speak first of the code as a reference book in itself. It has been said many times before that the catalog is the reference librarian's most important tool but I think 
now that the code is a very important supplement to it and that a copy should be on hand at every reference desk.

\section{Reference Uses of Code}

It can be used in two ways: (I) To explain to a baffled user of the catalog some obscure entry. For instance, the entries for some parts of the church liturgies, as the Ambrosian rite, are frequently questioned. There in the code is a clear and concise outline of the liturgies of the Catholic and Eastern churches. Upon showing this and the many examples of entries of the liturgies to the inquirer, the entry seems more reasonable. Even the fact that the Home Owners Loan Corporation is entered under Home while the Rural Electrification Administration is under U.S. Rural Electrification Administration seemed clear to an inquirer when I showed him the explanation in the code and the examples for the difference. (2) Another reference use of the code is for the information which it contains in itself. The glossary is useful for students who are compiling bibliographies. I recently found the definition of the term "broadside" very satisfactory.

The outline of the masonic organization is a fine piece of reference work. The sections on foreign compound names and the explanation of the make-up of a Hungarian married woman's name are worth remembering. The transliteration tables are useful. Frequently the sources of the information are given and thus further detail may be located.

I might enumerate many more such examples but I must go on to the second consideration of the code from the reference point of view, i.e., "What do the users of the catalog in a university library want from the catalog card?"
For libraries already using the complete Library of Congress cards, the code does not change things in any appreciable degree, but before accepting the code it may be well to consider whether the entries advocated and whether all the details now put upon the cards by the catalogers are wanted by the user of the catalog. No adequate study has yet been made of this rather intangible question but it probably should be made. I can only give impressions gained from long experience and some instances which have occurred in the last two months. My impression is that every bit of information on the catalog card is used at some time and I believe that a close study would prove that the time saved for faculty, students, reference and order departments more than compensates for the time the catalogers take in looking up the information and putting it on the card once and for all time. It is true that some information and some cards are seldom used but other information is used with great regularity. In that large group of students and faculty who crowd around the catalog at all times, there are many who are just using it as a finding list, but I think there are always a few who are looking for a diagram, a facsimile, a very special edition of an author's works, or in some way using the detailed and so-called reference material. Also in a university library one never knows when a scholar who knows more about a subject than anyone else in the world is going to appear at the catalog and make use of some fine point.

Since I realize that some shortening of the cataloging may be necessary in some cases, I will speak first of the parts I should like to see continued at all costs and then some parts I should be willing to see curtailed if necessary. 


\section{Author Entry}

I. Author entry. In this day of union catalogs, cooperative catalogs, and interlibrary loan, it is necessary that all cooperating libraries keep their main entries in agreement as much as possible. A book cataloged under an unusual entry is as good as lost in a union catalog. With the expanded rules and the many examples given in the code, it should be easier for libraries to keep their entries consistent. The examples given under corporate entries seem especially apt.

In a university library, for the personal author entry, we need, in most cases, the author's full name and his dates. Aside from its purpose of distinguishing persons of the same name for filing and entry, the purpose of dates is largely for reference use. However, I believe this is one kind of reference information on the card that is used by all kinds of users of the catalog -undergraduates, research workers, faculty, reference, order, and catalog departments. For speed in use and for accuracy, the information on the catalog cards surpasses all biographical dictionaries. If more information is desired, it is easier from this information to locate the right biographical dictionary or an obituary. I am frequently impressed with the accuracy of the dates on the Library of Congress cards. Recently a member of our faculty was looking for the birth date of Mrs. Nathaniel Hawthorne. The Library of Congress cards gave one date but several biographical dictionaries were consulted and a life of Mrs. Hawthorne by her son gave a date two years later. We then began an extensive search in the vital records of Massachusetts, in the printed church records, and obituary notices and found that the date in these sources agreed with the date on the Library of Congress cards. If it had not been for the Library of Congress cards we would have used the date used by her son and thus perpetuated the mistake. I am wondering where the cataloger at the Library of Congress found her information and how much time she took with the question. However much, I am grateful to her!

An edition printed after an author's death sometimes leads the reader astray if the author's dates are not given. I once heard a reader say he always looked at the author's dates on a card when getting a book because he was interested to see how old the author was when he wrote the book.

The rule in the code now reads "add the dates of birth and death in the heading when they can be discovered with a reasonable amount of search." I should like to see the interpretation of this rule stretched to the limit in many cases. It is true that the information might be found easily in some new reference book ten years hence but think of the number of people who are going to search through volume after volume of Who's Who in the meantime.

\section{Added Entries}

2. Added entries. This section in the code has been expanded but I believe it could be expanded still more. To me added entries are more important than the subject cards. A book is quoted by the name of its editor, joint author, illustrator, translator, by its title, partial title, the body sponsoring its publication-anything the reader or writer can remember offhand, and often the subject cannot be definitely determined from the fragmentary reference. Our order department has found that books are so often offered in dealer's catalogs, not by the name used in our main entry but by some added entry, that many added en- 
tries are now put in the official catalog for their benefit.

\section{Analytical Entry}

3. The analytical entry. The value of the analytic card in any library varies with the ease with which the information may be found elsewhere in that library. Sometimes a set is well analyzed in a bibliography, an index, or the publisher's catalog, and it is not necessary to duplicate the work. Other times these analytical entries are priceless. I am reminded of a recent search for a memorial lecture which was hidden in a set which was privately printed. We are frequently able to locate, through a Library of Congress analytic, a book in our own library in a set not analyzed in our catalog. Offhand I should say that the code gives the form for every possible kind of an analytical entry but the question of what to analyze must be settled by each library. I believe this is a question that might be settled by the catalog department after consultation with the reference department.

\section{Description of the Book}

4. Part 2 of the code is devoled to the description of the book-the transcription of the title, the imprint, the collation, the size. All of these rules have been expanded and the examples cover many complicated pagings and exceptional imprints. Individual libraries may adopt as many or as few of the rules as they wish, but no doubt it will save time for all catalogers to have this more or less routine part of the work so definitely laid out. For a university library, I believe most of the details described are both useful and necessary.

It is true an undergraduate needs only the simple pagination when he is looking for some book which is not too long or when he is required to read three hundred pages on some subject. On the other hand the detailed pagination is necessary in identifying the book as the one quoted in a bibliography or in differentiating editions. Recently one of our faculty members wished to consult all the editions and issues of the works of Mme. de Staël for the sake of comparing the change in public attitude towards certain passages. We found that several editions were printed the same year and differed only slightly in paging but through the detailed pagination found on our depository cards and the cards in the union catalog of the Library of Congress we were able to borrow for him on interlibrary loan almost every known edition or issue. I speak of this instance because it was not a question of rare books, and it was the contents and not the bibliography which interested the reader.

Of course the detailed pagination on the Library of Congress or some other equally detailed card is frequently invaluable for the comparison of our copy of the book with another copy. With the detailed pagination given for single volumes, it is disappointing to see in this code that the same rule stands concerning the omission of the pagination of works of more than one volume. For identification, for interlibrary loan, for microfilming, for an idea of how completely a subject is covered, we need this information as much for works of two volumes as we do for works of one volume.

\section{Collation}

The section on the collation of illustrations, plates, portraits, facsimiles is very detailed-too detailed for many libraries no doubt. However, I believe all of this information is used and saves time in a uni- 
versity library. It is much quicker to find a facsimile of a page of Beowulf in the Anglo-Saxon from the card catalog than it is to go through three shelves of copies of Beowulf to find such an edition. Usually a reader does not care if the map, portrait, or diagram he is looking for is a frontispiece or not, but since the term "frontispiece" helps to identify the book or the edition, this information might as well be included.

All of this detailed description is used constantly by the order department for it is only through a careful comparison of the paging, size, illustrations, etc., that they can be sure the edition offered for sale in a dealer's catalog is not one already in the library, or the copy they buy is complete. So-called new editions often turn out to be not so new when a comparison of the collations is made.

\section{Notes}

5. Just one more point on the description of the book-this is the question of notes. Although there are many useful suggestions as to the form of the note in the code, the cataloger must decide when to make one. A little note often gives a clue which solves the whole reference problem. The note that the book has been published under another title, that it is extracted from some journal, that it was published in a limited edition, that the text is in Russian and German, or, in the case of a translation, the note which gives the original title-all these are used so frequently that we forget to be grateful to the catalogers for the information. We also find the fuller notes in the information cards very useful. I was interested to see in the code the detailed directions for an information card concerning unnumbered international or national congresses. The proceedings of these congresses are so complicated that an information card supplying the number and dates of all the congresses is a great help in convincing a reader that a seemingly broken set is complete. This information is frequently very difficult to find elsewhere, but the cataloger has run it down from many sources and recorded it once and for all.

\section{Items to Give Up}

So much for the points of the code and the catalog which a reference department of a university library likes to see emphasized. The question now arises what are we willing to give up? Some of the points I have suggested as I have gone over them, but let me enumerate.

( I) The cards which might be omitted from the catalog. (a) We do not need series cards for long series for which there are published indexes such as the publications of the Carnegie Institution, the publications of the Department of State and other government offices, or the series cards for publishers' series which are easily found in the publishers' catalogs. (b) We do not need analytic cards for sets analyzed in good bibliographies.

(2) Information which might be omitted from the card. (a) Reference librarians do not need contents notes for books indexed in the standard indexes-as the Essay Index, the Short Story Index, the Drama Index, or for books like Caffin's History of American Painting where the title indicates pretty well the contents. We do need contents notes for an author's collected works which has no index of its own or for composite works not indexed elsewhere. (b) We do not need to have the author's name repeated in the body of the card unless some further information is added thereby. If feasible, I should like 
to see the names of both of the joint authors of a book put in the main entry and their names not repeated in the body of the card. This would be less confusing to many users of the catalog and also less irritating to the joint author, or to the joint author's friend, for so often it is the joint author who has done most of the work on the book and then finds his name relegated to the middle of the card and an added entry. However, I believe this would not save time for the cataloger who would have difficulty in finding room for this information at the top of the card or later in adding information to the main entry if additional information were found.

(c) Most libraries do not need such detailed cataloging of serials. Now that we have the Union List of Serials with its fund of information concerning changes of titles and indexes, we do not need all of this information repeated on the cards. There is, however, one important item on the card which is not in the Union Listthat is, the names and dates of the editors and I hope the catalog will continue to give this information. Frequently we need this hidden information for editors of foreign periodicals and for American periodicals published before Ayers or not listed in Ayers.

(3) The code is not concerned with subject headings, but while mentioning cataloging cuts I should like to say that I feel that a judicious omission of many of the subject cards would be the least serious of all the possible cuts in cataloging.

\section{Brief Cataloging}

(4) My last suggestion is that certain types of material be cataloged very briefly -that is, foreign dissertations, certain pamphlets and processed materials (some are probably not worth even brief cataloging), government documents which have their own indexes, and books of little consequence which just drift in. Books on subjects not pertinent to the particular library might also have a form of brief cataloging. All of this material must be sorted by a competent person with unusual judgment and it is very necessary to decide on a practical system of brief cataloging which will stand the test of time. If the work has to be done over, there is no time saved. At the university we have had several successive methods of brief cataloging for foreign dissertations. Until recently each time a foreign dissertation was wanted, we had to decide first which method was in use when the thesis was written and look for it under that method, or, more often, look for it under all methods. Our reference department is convinced that no time was saved for the library.

\section{Full Code Be Adopted}

In conclusion, for university libraries, I should like to urge that the code be adopted about as full as it is-some parts expanded and other parts changed as catalogers might agree. Especially, I should like to see the Library of Congress adopt the code, or at least keep on with the parts of it which it is now using so that no matter what other libraries do in the way of shortening the information on the card, the depository cards will give the full information. If the Library of Congress cannot keep up with this work, I feel that other large libraries should help to subsidize this work. Without this full information on our own cards or on the depository cards the work of our reference department would be seriously handicapped and would require more help to do the same work we are doing today. 